\title{
Acerca de la destrucción de Giribaile
}

\author{
Luis María Gutiérrez Soler ${ }^{1}$, Raúl Manchón Gómez², \\ Francisco Pérez Alba ${ }^{1}$
}

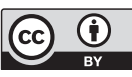

Recibido: 10/04/2020

Aceptado: 29/11/2020

\section{Resumen}

El presente artículo contrapone la arqueología científica actual del proyecto Giribaile con la arqueología filológica decimonónica. La confrontación entre cultura material e interpretación interesada de las fuentes escritas toma como escenario de fondo la localización de ciudades reales o inventadas como Orongis, Baecula, Silpia o Helinga. Resulta importante observar la resistencia del discurso arcaico presente en las tradiciones orales de las comunidades locales.

Palabras clave: Hierro II; cultura ibérica; romanización; Guadalquivir; Sierra Morena; toponimia antigua

Abstract. On the destruction of Giribaile

This article confronts the current scientific archeology of the Giribaile project with nineteenth-century archeology. The confrontation between material culture and interested interpretation of written sources takes as a background scenario the location of real or invented cities such as Orongis, Baecula, Silpia or Helinga. It is important to observe the resistance of archaic discourse present in the oral traditions of local communities.

Keywords: Iron Age II; Iberian culture; romanization; Guadalquivir; Sierra Morena; ancient toponomy

Gutiérrez Soler, Luis María; Manchón Gómez, Raúl; Pérez Alba, Francisco. «Acerca de la destrucción de Giribaile». Treballs d'Arqueologia, 2020, núm. 24, p. 165-184. DOI: 10.5565/rev/ tda. 113

La publicación de este volumen centrado en los conflictos armados de la segunda guerra púnica parece una buena oportunidad para debatir, ordenar secuencias de argumentos y ofrecer algunas reflexiones sobre el final de la población que una vez se alzó sobre el extremo del promontorio de Giribaile (Vilches, Jaén; figura 1) y su

1. Universidad de Jaén. Instituto Universitario de Investigación en Arqueología Ibérica. Imsoler@ujaen.es; fpalba@ujaen.es

2. Universidad de Jaén. Departamento de Lenguas y Culturas Mediterráneas. Área de Filología Latina. rmanchon@ujaen.es 


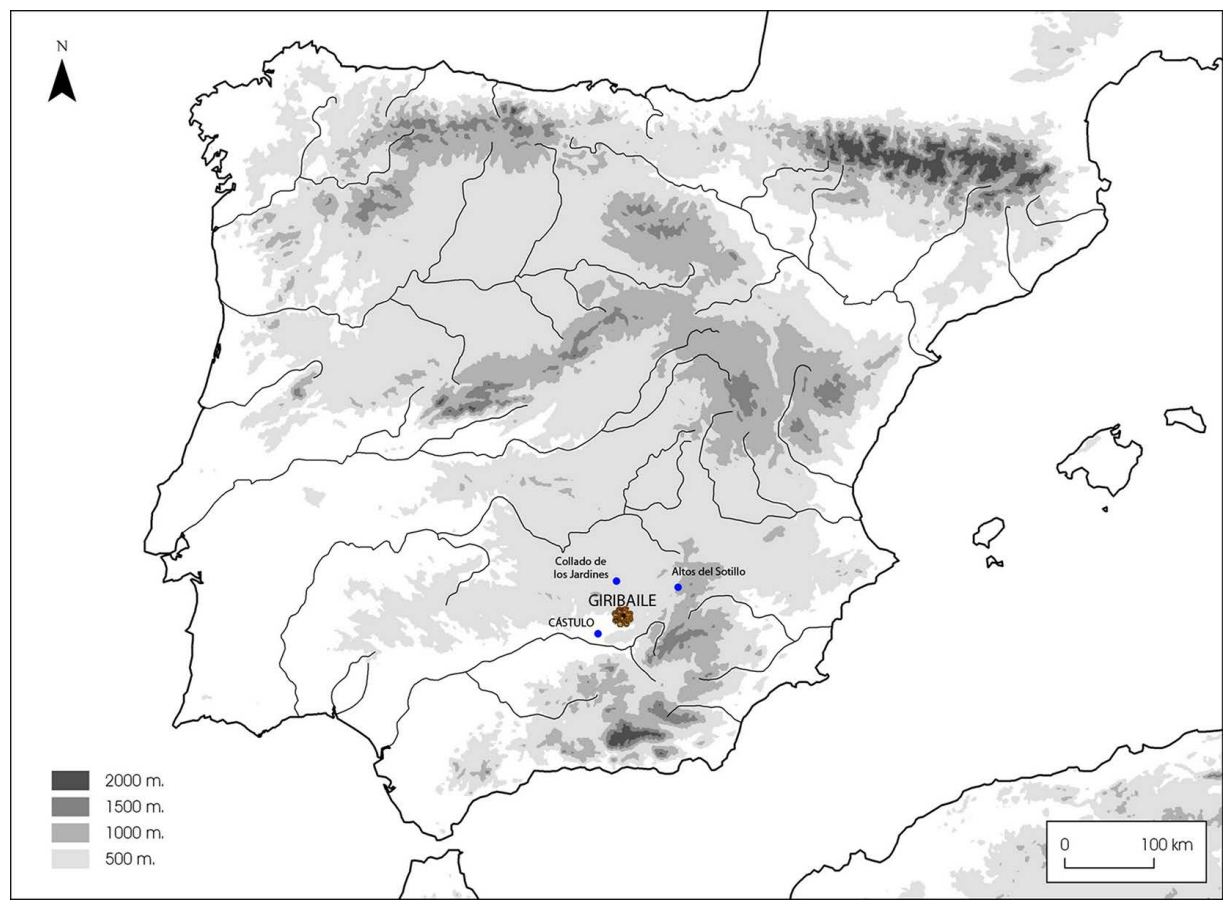

Figura 1. Localización de Giribaile en el territorio de Cástulo.

posible vinculación con la conquista romana. Primero con Giri ${ }^{3}$, ciudad supuestamente citada por Plutarco, como protagonista de una acción de castigo concreta de la vida de Sertorio, y, más tarde, con Orongis, ciudad que fue asediada y vencida a manos de Lucio Escipión en el 207 a. C. ${ }^{4}$ Además, en su entorno más inmediato el profesor Manuel de Góngora también ubicó las ciudades de Helinga y de Silpia, opción que actualmente parece completamente descartada.
Ahora más que nunca, después de treinta años prospectando su territorio $y$ finalizado el proyecto general de investigación autorizado por la Junta de Andalucía a seis años, se hace imprescindible hacer un poco de historiografía sobre el propio proceso de trabajo y valorar la complejidad de la interpretación, creciente con cada nueva campaña de excavación (figura 2).

3. «¿Dónde localizaremos a Giri, la ciudad bárbara que inmortalizó Plutarco en la vida de Sertorio?» (Góngora, 1860: 5). «En la meseta de sitio tan excelente, se alzó, a mi parecer, sin duda alguna, la Giri de Plutarco» (Góngora, 1860: 8).

4. «En el oppidum de Iliturgi, Cerro Maquiz (Mengíbar), se hace referencia expresa a su destrucción en el año 206 a.n.e. y Giribaile, sufrió asedio y fue tomado por Lucio Escipión en el 207 a.n.e.» (Ruiz et al., 2015: 634). 


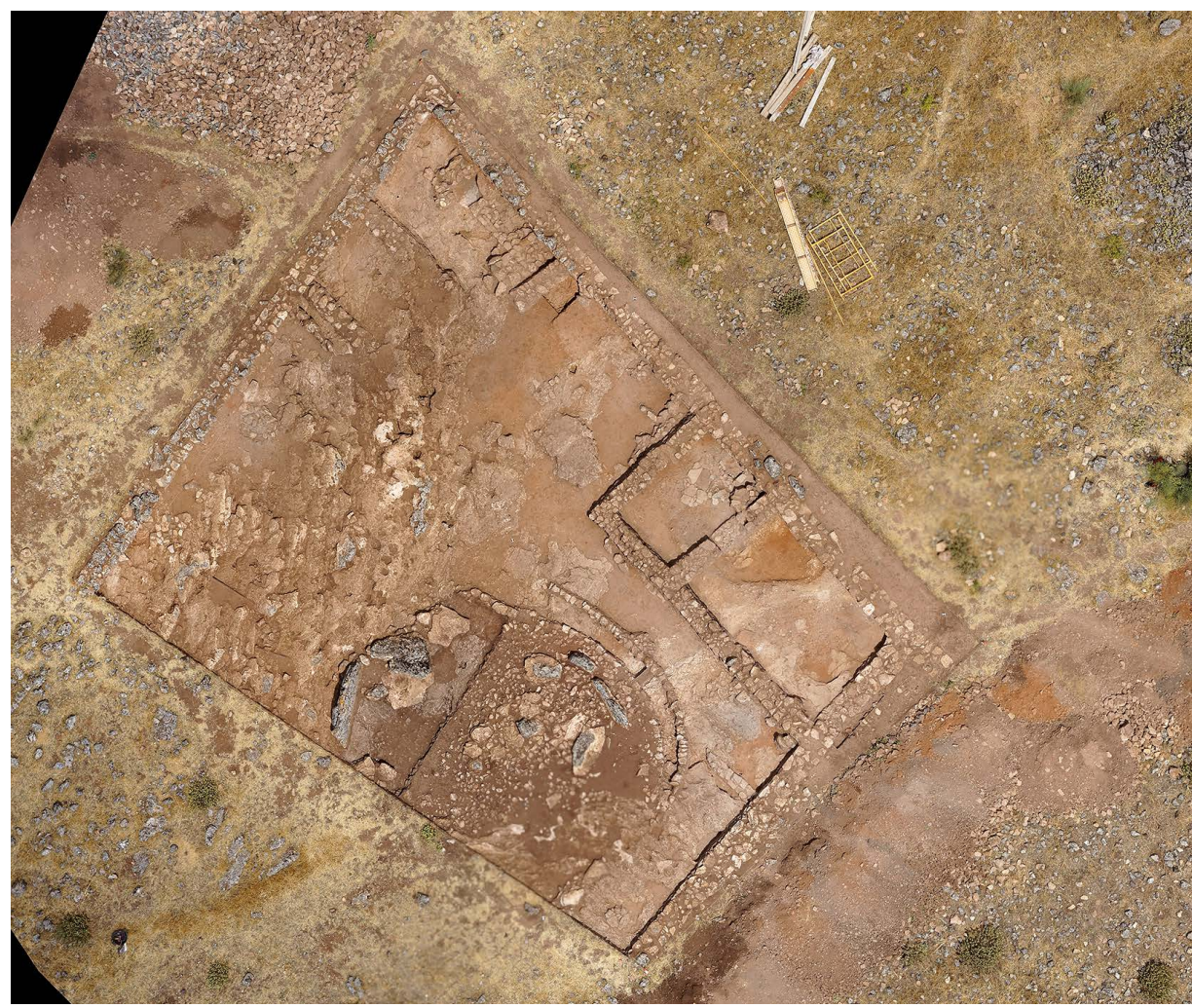

Figura 2. Área 3: primer corte autorizado abierto en la meseta de Giribaile en el año 2014.

\section{Lecturas desde una arqueología filológica}

Las fuentes escritas resultan muy valiosas para comprender e interpretar adecuadamente el proceso histórico que se relaciona con el estudio y análisis de un determinado sitio arqueológico. La identificación con un nombre concreto marca un hecho diferencial, al que en términos actuales podríamos calificar como un sello de calidad de aquellos lugares, importantes, que han dejado una huella escrita en la memoria histórica. Este hecho no pasó desapercibido en el caso de Giribaile, incluido en el selecto grupo de ciudades que $\mathrm{Ma}$ nuel de Góngora recorrió y describió en 1860, al que me atrevería a calificar de imprescindibles en la corografía de la provincia de Jaén. Giribaile, sin duda, es una de ellas.

La publicación en 1986 en el Boletín de la Asociación Española de Amigos de la Arqueología del artículo titulado $D e$ Giri a Guiribaile: análisis de una posible correspondencia entre Giri y Guiribaile, a cargo del egiptólogo francés Frédéric Servajean, en nombre también de su padre, Georges Servajean, que había dirigido las primeras campańas de excavación en la 
meseta de Giribaile a finales de la década de los años 1960, recuperó la propuesta realizada por el profesor Manuel de Góngora de situar en este lugar la ciudad limítrofe a Cástulo destruida por Sertorio y fijó por primera vez dos argumentos básicos sobre el conocimiento de este sitio.

El primero tenía que ver con la identificación del lugar con alguna de las ciudades citadas en las fuentes escritas de época romana, convencidos, como también lo estamos nosotros, de que una ciudad de esa entidad (más de 14 ha) y con una fortificación de tal envergadura (el dispositivo monumental de tipo barrera) debía haber dejado una huella en los anales de la conquista.

El segundo, a raíz de la valoración de determinados contextos de incendio (que no tuvo oportunidad de conocer Manuel de Góngora), tenía que ver con la consideración de que el final de la ciudad debía relacionarse con una destrucción violenta y generalizada. En última instancia, en la interpretación de Manuel de Góngora la valoración filológica (el deseo de identificar la ciudad con un pasaje histórico concreto recogido en las fuentes escritas) iba por delante de las precisiones cronológicas que podía proporcionarle un adecuado reconocimiento científico de la cultura material que recogió y catalogó en la meseta de Giribaile. Al respecto resulta interesante recordar las fotografías que publicó de ciertos fragmentos decorados a los que calificó como «restos de cerámica romana (que ofrece caracteres neolíticos)", entre los cuales se encuentran ciertas producciones de recipientes de almacenaje de gran tamaño con aplicaciones de reticulados incisos destacados sobre bandas, para los que aún hoy sigue siendo difícil establecer una adscripción crono-cultural precisa.

\section{Exégesis de los textos}

Las formaciones $\gamma v \rho \imath \sigma o l v \tilde{o} v$ (referida a los habitantes de la supuesta ciudad de Giri) y Orongis han sido objeto de controversia por tratarse de dos términos geográficos que sólo se documentan en Plutarco y Tito Livio. No pueden cotejarse ni confirmarse con otras fuentes como la epigrafía o la numismática y tampoco han tenido continuidad en época tardía o medieval. Como ocurre con no pocos topónimos y gentilicios de la Hispania antigua, la identidad lingüística de tales términos y su ubicación geográfica sigue siendo un quebradero de cabeza.

Para conocer su emplazamiento, a partir de los datos filológicos y arqueológicos, es imprescindible estudiar previamente la realidad textual de tales denominaciones en la transmisión manuscrita de Plutarco y Tito Livio. Ello supone no sólo recurrir a las mejores ediciones críticas de estos autores, sino, sobre todo, rastrear las variantes gráficas de dichos términos para tratar de determinar la forma correcta o genuina del topónimo o, al menos, la preferible o más cercana a la forma original, cuestión a la que no siempre puede darse una respuesta satisfactoria. Además, el exotismo y rudeza fonética de los topónimos hispanos prerromanos debió de provocar problemas de transcripción al latín y al griego y pudo alterar el aspecto formal de los términos originales o, incluso, deformarlos para que su pronunciación resultase más fácil a oídos latinos o griegos (Dolç, 1953: 178-181).

\subsection{Los girisenos de Plutarco (Plut., Sert., 3, 6) \\ El nombre «girisenos» o "guirisenos» ( $v 0 \rho \imath \sigma o \imath v \tilde{\omega} v$, en genitivo plural, entre}


otras variantes de lectura) es un término un tanto singular. Solo se documenta una vez en un pasaje de la Vida de Sertorio de Plutarco (Plut., Sert., III, 6) como gentilicio de los habitantes (calificados como $\beta \alpha ́ \rho \beta \alpha \rho o l)$ de una localidad cercana a Cástulo.

El suceso que enfrentó a los castulonenses y sus aliados los girisenos contra los romanos acuartelados en Cástulo solo está atestiguado en la vida de Sertorio, texto compuesto por Plutarco entre finales del siglo I d. C. e inicios del s. II d. C. Los hechos referidos por Plutarco son, por tanto, muy anteriores a la propia época del autor griego, por lo que necesariamente tuvo que recurrir a alguna de las muchas fuentes historiográficas que narraron las acciones de Sertorio, seguramente las Historias de Salustio, de la que se conservan poco más de quinientos fragmentos. ${ }^{5}$ El episodio tuvo lugar durante el mandato (98/97-93 a. C.) del procónsul en Hispania Tito Didio. ${ }^{6}$ Sertorio, por entonces tribuno mili$\operatorname{tar}(\chi \imath \lambda i \alpha \rho \chi o \varsigma$, según Plutarco) de Didio, debió de ser el oficial al cargo de las tropas romanas que invernaban en Cástulo.

Si el vocablo no estuviera presente en varios de los manuscritos que nos han transmitido el texto de Plutarco, quizá no faltasen razones para pensar que estamos ante una 'palabra fantasma', fruto de alguna copia defectuosa, como ya advirtió Schulten en 1926 (ahora reedición de 2013: 305 n. 176). También puede tratarse de una forma corrupta, dado que la ortografía y los hábitos de los copistas provocan a veces lecturas falsas que co- rren el riesgo de convertirse en falsos elementos de vocabulario. En nuestro caso no estamos ante una aparición ocasional y aislada de un único manuscrito, dado que el término se documenta, con leves variantes gráficas, en todos los manuscritos que transmiten la biografía de Sertorio de Plutarco. Debemos, por tanto, prestar especial atención a la transmisión del vocablo en los manuscritos del texto griego de la Vida de Sertorio de Plutarco.

El primer problema que se plantea es la fijación del texto en lo que a nuestro término se refiere. Llegar a determinar lo que el autor pudo escribir aquí se presenta como una labor difícil, dadas las diversas circunstancias que concurren en el caso. Por un lado, están las dificultades de la edición del texto de Plutarco, con una historia manuscrita bastante compleja. A ello se suma la propia naturaleza del vocablo, sobre el que parece pesar una voz no griega ni latina. La vacilación que se observa en los manuscritos puede estar motivada también por la falta de uniformidad a la hora de transcribir préstamos o adaptaciones de otros idiomas al griego. Incluso, cabe pensar que Plutarco leyó el término en una fuente latina y lo helenizó como mejor le pareció. Con todo esto, es imposible reconstruir la genuina forma original.

Para abordar el reto de la propuesta de localización de la ciudad de los girisenos se debe aceptar previamente y de manera forzosa que la denominación

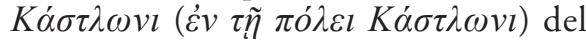
testimonio de Plutarco corresponde al de

5. Sobre las fuentes empleadas por Plutarco en la composición de la vida de Sertorio véase, en especial, Konrad (1994: 41-56).

6. Sobre este episodio vid. Góngora (18609; Konrad (1994: 48-51); García Morá (1991: 160-167 y 489 491); Pérez Vilatela (1994); Schulten (1926 (2013):86-88 y 305, n. 176); Servajean (1986) y García Morá (1991: 179), que sitúa el incidente entre el 97 y el 95 a. C. 
la ciudad de Cástulo, ya que los girisenos eran sus vecinos ( $\dot{\alpha} \sigma \tau v \gamma \varepsilon i \tau o ́ v \omega v)$, como se dice expresamente en el texto. Por otro lado, Plutarco emplea el término $\pi \delta ́ \lambda ı \varsigma$ para referirse tanto a la localidad en la que habitan los girisenos como a la de Cástulo. ¿Quiere esto decir que la ciudad de los girisenos era una ciudad de cierta importancia más que un pueblo pequeño, como ya señaló Servajean $(1986,38)$ ? ¿Es $\pi$ ó $l \varsigma$ simplemente un término genérico para referirse a cualquier localidad, tenga o no entidad? No sabemos aún con certeza y, tal vez, nunca podamos saber quiénes eran estos girisenos y dónde estaba la $\pi o ́ \lambda l \varsigma$ en la que vivían, como se preguntaba Schulten y, más tarde, Pérez Vilatela (1994: 3) y, recientemente, Landucci (en Plutarco 2004: 216-217, n. 24). En cualquier caso, como ya hemos indicado, la ciudad debió de encontrarse muy cerca de Cástulo, pues «el asalto fue planeado y ejecutado la misma noche» por una comunidad vecina, como ya advirtió Adolf Schulten en 1926 (2013: 87 y 305, n. 176) y al que han seguido Servajean $y$ otros autores.

De los nombres que conocemos de dicha región ninguno corresponde al de los girisenos, en opinión de Schulten. Ahora bien, el oppidum de Giribaile podría estar emparentado fonéticamente con el de los girisenos, aunque el topónimo se relaciona también con una leyenda que Gonzalo Argote de Molina recoge en su obra $\mathrm{La}$ rica hembra, en la que este nombre se hace derivar de un tal Gil Baile, perteneciente a un linaje de la ciudad de Baeza en el siglo XvI; por tanto, el asunto merecería un estudio más detenido.

En cuanto a la propuesta de identificar la ciudad de los girisenos con la de los

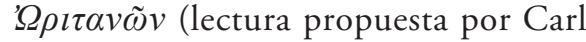
Sintenis en 1841 a partir de Esteban de

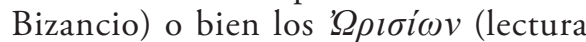
de Moses du Soul o Solanus en 1729), ambas deben ser rechazadas, como ya señaló Schulten (2013: 305, n. 176), porque "Oretum se encuentra a $70 \mathrm{~km}$ de Cástulo». ${ }^{7}$ También se ha propuesto, creemos que con poco fundamento, la

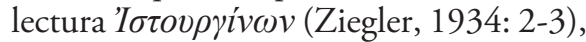
lo que supondría ubicar la ciudad en $I s$ turgi (la actual Los Villares, en Andújar).

\subsection{La urbs de Orongis de Tito Livio (Liv., 28, 3, 1-3 y 28, 4, 2)}

El único testimonio del topónimo Orongis (Orongin, en acusativo, en el texto que lo transmite) es el que figura en dos pasajes de la obra $A b$ Vrbe Condita del historiador latino Tito Livio (59 a. C.-17 d. C.) y, más concretamente, en el libro 28 , en el que se narran los últimos ańos de la segunda guerra púnica (207-206 a. C.). Según Livio, esta ciudad hispana (Hispanae gentis) era la más rica o próspera (opulentissima) de su comarca (in iis locis). Sus habitantes (incolae) trabajaban una tierra fértil (ager frugifer), además de sus minas de plata (argentum etiam... fodiunt). ${ }^{8} \mathrm{Te}$ nía murallas (muros, moenia) y había servido de baluarte o fortaleza ( $a r x)$ para las

7. Según Schulten 1926 (2013: 305, n. 176), el nombre transmitido (Gurisoinon) está seguramente corrompido. El nombre debió de sonar de manera muy parecida a Cur-iga (Extremadura). La raíz Curestá también presente en Curense y Curunda.

8. La frase ager frugifer; argentum etiam incolae fodiunt resulta un tanto particular, aunque la tradición manuscrita es unánime y no hay variantes de lecturas. El ager frugifer puede ser un nominativo absoluto o bien hay que sobreentender el verbo est; por su parte, en la segunda parte de la frase el adverbio etiam puede entenderse como «también» o como «además». 
campañas militares de Asdrúbal contra los pueblos de la zona.

Aunque desconocemos el número de habitantes de esta próspera ciudad, hay que suponer que fue muy poblada, a tenor de la cifra de muertos durante el ataque (oppugnatio) de Lucio Escipión: casi dos mil bajas (hostium duo milia ferme) a las que hay que sumar unos trescientos prisioneros (oppidanorum... trecenti). Importante fue también el número de soldados romanos que intervinieron en la conquista de Orongis: diez mil hombres de infantería y mil de caballería (decem milibus peditum, mille equitum), una cifra ciertamente significativa y elevada, aunque para Lucio Escipión las fuerzas romanas eran muy escasas en comparación con las de los habitantes de Orongis. ${ }^{9}$ Ahora bien, tal proporción numérica debe tomarse con cautela. Especialmente relevante es el hecho de que la hazaña de la conquista de Orongis fuera equiparada a la conquista de Cartagena por el hermano de Lucio, el célebre Publio Cornelio Escipión, el Africano.

La importancia que Livio asigna a la conquista de Orongis tal vez deba ser interpretada como una «amplificación literaria muy lejos de corresponder a la realidad histórica», en palabras de Yelo (1991-1992: 175). El historiador perseguía con ello magnificar las hazañas de los
Escipiones, lo que, en nuestra opinión, no significa que haya que poner en duda la existencia real de Orongis y, menos aún, su preeminencia como urbs opulentissima, como la califica Livio. En cualquier caso, la extensión y el pormenor con que se narra el asedio y conquista de la ciudad sugieren que la fuente de información empleada por el historiador pudo ser de primera mano y con una gran fidelidad a los hechos.

Respecto a la consideración de Orongis como urbs, hay que señalar que Livio emplea ese término en diez ocasiones para referirse a esa localidad al tratar este episodio de la conquista. Sólo en dos momentos muy puntuales (en la última fase del asedio romano) el historiador recurre al término oppidum para enfatizar, seguramente, que se trata de una ciudad fortificada. ${ }^{10}$ Ignoramos si es un mero sinónimo de urbs, usado por variatio estilística, o si tiene aquí el valor específico de arx o plaza fortificada elevada, que es lo que creemos que quiere decir. Téngase en cuenta que en el latín de los historiadores el sustantivo oppidani suele designar a los habitantes de una población fortificada que ha sido asediada y, por ende, es sinónimo de «asediados». ${ }^{11}$ Además, en el propio texto de Livio se indica que la ciudad de Orongis había sido la fortaleza (arx) desde la que Asdrúbal hacía incur-

9. Animaduertit Scipio nimia paucitate suorum exaequatum certamen esse et iam eo superare hostem quod ex muro pugnaret, «Escipión se percató de que por el reducido número de los suyos se había desequilibrado el combate y que el enemigo ya les superaba porque luchaba desde la muralla» $(28,3,8)$.

10. Timor inde oppidanos incessit ne, si hostis urbem intrasset, sine discrimine Poenus an Hispanus esset obuii passim caederentur; itaque patefacta repente porta frequentes ex oppido sese eiecerunt, "Luego se apoderó de los habitantes el temor de que, si el enemigo entraba en la ciudad, morirían todos los que encontraran sin distinción de cartaginés o hispano» (Liv., 28, 3, 10; trad. de Gascó, en Livio, 1992: 257). Más adelante, concluido ya el asedio, dice Livio: Carthaginienses omnes in custodiam dati sunt, oppidanorum quoque trecenti ferme qui clauserant portas; ceteris traditum oppidum, suae redditae res, «Todos los cartagineses fueron hechos prisioneros y también unos trescientos habitantes de la ciudad que habían cerrado las puertas; la ciudad fue entregada a los otros y sus bienes les fueron restituidos» (28, 3, 15; ibid: 258).

11. Vid. Ernout-Meillet (2001), s.v. oppidum: 463. 
siones a los pueblos del interior, es decir, ocuparía «una posición estratégica bien fortificada», como sostiene Yelo (19911992: 174). En cualquier caso, el término arx también es aplicado por Livio a ciudades tan dispares como Cartagena (26, 43, 8 y 26, 48, 4: munitissima arx), Iliturgi $(28,20,1)$, Sagunto $(21,11,10$ : castellum in ipsa urbe velut arcem imminentem) y Castrum Album $(24,41,3)$.

No falta tampoco en la descripción que Tito Livio hace de la ciudad de Orongis el uso del término forum, ${ }^{12}$ lo que supone aplicar, de forma un tanto anacrónica y tal vez para dar mayor realismo al relato, un concepto exclusivamente romano a una población no romana, lo cual no significa que en Orongis no existiera algo parecido a un foro como un elemento más de la configuración e importancia urbana de esta opulentissima ciudad. A tenor de lo expuesto, no cabe duda de que el rasgo que Livio trata de destacar especialmente de Orongis es que era una población poderosa.

Respecto al origen del topónimo, no es posible descubrir la lengua a la que pertenecen los barbari que, según Livio, llamaban (appellabant) a su ciudad con el nombre de Orongis. La fórmula appellabant y afines (vocabant, vocant) es empleada por Livio en bastantes ocasiones para introducir topónimos o nombres no latinos. La forma con -s final Orongis puede responder a un topónimo indígena latinizado y sería un morfema ajeno a la lengua autóctona, pero añadido por los romanos para «normalizar» el nominativo (como hicieron en el caso de Calagurris). Se la suele identificar con Aurgi / Jaén (Serrano, 2004), pero también con Auringis, aunque no hay razón lingüística para hacerlo. ${ }^{13}$ Posiblemente, esta ciudad bastetana quedaría fronteriza de la región oretana y estaría en la misma zona que Aurgi.

\subsection{Silpia y Helinga}

Conviene aclarar que la forma Helinga es una mera transcripción de la forma griega $H \lambda i \gamma \gamma \alpha \varsigma$ empleada por Polibio, mientras que el vocablo Silpia, acompañado del término $u r b s$, se encuentra únicamente en un pasaje de la obra de Tito Livio como denominación de un lugar de Hispania en el que se concentraron las tropas de infantería cartaginesas antes de enfrentarse con los romanos: peditum septuaginta milia quidam adducta ad Silpiam urbem scribunt (Liv., 28, 12, 14). Según Livio, en ese lugar acamparon los cartagineses, tomando posiciones en las llanuras o campos abiertos: Ibi super campos patentes duo duces Poeni ea mente ne detractarent certamen consederunt (Liv., 28, 12, 15). A tenor de lo que más adelante narra Livio al describir el desarrollo de la batalla, dicho lugar no debió de estar muy lejos de Cástulo y Baecula (Liv., 28, 13, 4 y 5).

Silpia es la lectura que transmiten los mejores y más antiguos manuscritos, entre los que se encuentra el famoso codex $\mathrm{Pu}$ teanus (Paris lat. 5730), del siglo v d. C. En manuscritos más recientes se encuen-

12. Liv., 28, 3, 13: Aliis partibus securibus dolabrisque caedebantur portae et refringebantur, et ut quisque intrauerat eques, ad forum occupandum, ita enim praecepto erat, citato equo pergebat: «En otras zonas de la muralla se abatían y rompían las puertas con hachas y picos, y según iba entrando cada jinete, marchaba al galope a ocupar el foro tal como se había ordenado» (traducción de Gascó en Livio, 1992: 257).

13. Villar (2014: 105) sostiene con un simple cambio [au]>[o] la identificación con Auringi (y de esta con Aurgi, v. Auringis), pero de hecho parte de una forma Oringi que no está documentada ni tampoco parece aceptable un cambio de timbre (i>o) en vocal tónica, como argumenta Correa (2016: 413, s.v. Orongis). 
tra la forma, al parecer corrupta, Salapia. Los estudiosos sostienen que en lugar de Silpia debe leerse Ilipa, transcripción latina de un topónimo indígena latinizado $y$, de aquí, helenizado en " $I \lambda l \pi \alpha$, que es la forma que emplea, en cuatro ocasiones, Estrabón. ${ }^{14}$ La razón por la que debe leerse Ilipa y no Silpia se basa tanto en el testimonio de Polibio $(11,20,1)$ como en otro pasaje de Livio $(35,1,11)$ donde se menciona la ciudad de Ilipa (pugnatum haud procul Ilipa urbe est), asociación que nos parece un tanto forzada. En el caso del texto de Polibio, conviene tener en cuenta que la única forma transmitida

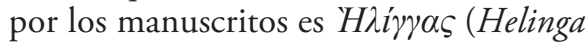
en transcripción latina) corregida en $H \lambda i \pi \pi \alpha \varsigma$ por los editores modernos. La corrección se basa a su vez en el texto de Livio, por lo que estaríamos ante una conjetura basada en un círculo vicioso que merecería ser revisada. Tampoco es muy clarificador el testimonio de Plinio el Viejo, pues la lectura de los manuscritos es Ilpa, en lugar de Ilipa (Plin., 3, 11). En el caso de que aceptemos la forma Ilpia, habría que ubicar el lugar de la batalla descrita por Livio (y Polibio) en Alcalá del Río o cerca de Carmona, a tenor de los hallazgos epigráficos encontrados en la zona.

\section{La interpretación del territorio según Manuel de Góngora}

La entidad de los restos conservados en la meseta de Giribaile está en el origen, sin duda, de esta propuesta que se suma, a otras tantas, de restituir algunos de los episodios bélicos más señalados que tuvieron lugar en el alto Guadalquivir a finales de la segunda guerra púnica. La ciudad, aunque a la sombra de la capitalidad de Cástulo, destaca en el territorio por su tamaño (figura 3) y debería relacionarse con el nombre de algunas de las ciudades que se mencionan en los conflictos de la segunda guerra púnica. En su descripción de Giribaile, el propio Manuel de Góngora asume por dos veces su relevancia con expresiones como «esta fortaleza que tuvo importancia durante las guerras púnicas» $\mathrm{y}$ «debió hacer gran figura en las guerras púnicas», asociando este hecho con el hallazgo de monedas autóctonas e ídolos de marcado carácter ibérico (Góngora, 1860: 6-7).

\subsection{Los escenarios}

El profesor Manuel de Góngora, seguramente condicionado por la edición de las fuentes clásicas que manejó, se propuso la localización de algunas de las ciudades antiguas que allí se mencionaban a partir de una pionera actuación de prospección en solitario.

La identificación de Giri se completa en el paisaje antiguo imaginado por $\mathrm{Ma}$ nuel de Góngora con dos ciudades contemporáneas en tiempos de la segunda guerra púnica, Silpia y Helinga, supuestamente localizadas en el llano y caracterizadas como los centros de ocupación principales de cada uno de los dos valles que configuran las vegas y rodean, por uno y otro lado, la meseta de Giribaile.

14. Correa (2016: 334-335, s.v. Ilipa), donde se indican todos los testimonios desde época republicana hasta Ptolomeo. Uno de ellos se encuentra en la llamada Cosmografía del anónimo de Rávena (texto tardío del siglo viII d. C., probablemente), donde aparece con h- inicial (Hilipa), fruto, al parecer, de un error gráfico. En testimonios numismáticos y epigráficos, desde el siglo II a. C. sólo se documenta el adjetivo Ilipensis-e y no el sustantivo Ilipa, del que derivaría el gentilicio. 


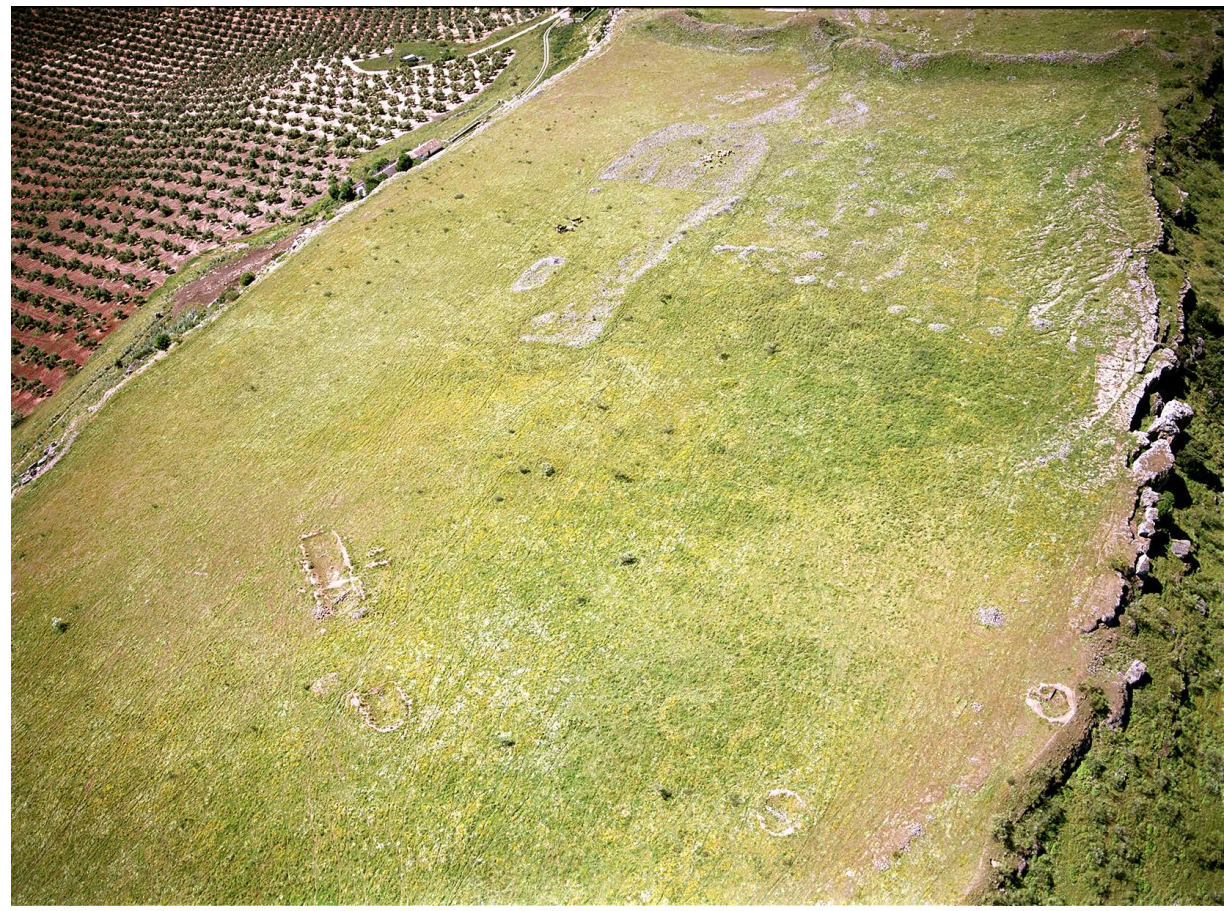

Figura 3. Vista aérea de la meseta de Giribaile. Imagen de la plataforma principal en la que se aprecian restos de las antiguas campañas de excavación, el poblado intramuros y el dispositivo de la fortificación de tipo barrera.

Sobre Silpia, Manuel de Góngora proporciona referencias precisas para localizar el enclave de la ciudad donde los cartagineses estuvieron acampados (Góngora, 1860: 375), ya que sus ruinas las sitúa a la orilla derecha del Guadalimar, en los terrenos conocidos como los Batanejos, en la jurisdicción de Vilches, a una legua de Canena (Góngora, 1860: 376-377). El área arqueológica de La Monaria (Gutiérrez et al., 1999) cumpliría con la mayor parte de estos requisitos, sin poder confirmar el topónimo, que no ha sido recogido en los mapas actuales. Desgraciadamente, no se ha conservado el plano de las ruinas de la supuesta Silpia al que hace referencia Manuel de Góngora en su Viaje Literario.
Comenta la existencia de edificios que se aprecian fácilmente sobre el terreno, ocupando una extensión de más de $800 \mathrm{~m}$. El plano de La Monaria (figura 4), elaborado a principios de la década de los años 1990, recoge una sucesión de construcciones exentas formadas por viviendas dotadas de amplios patios, cuyas plantas resultaban fácilmente reconocibles por mera inspección de la superficie del terreno.

Respecto a Helinga, Manuel de Góngora ubica esta ciudad en Arquillos el viejo (Góngora, 1860: 376) lugar en el que se levanta un cortijo actual que conserva la memoria de una antigua posada derribada hace pocos años. La mejora de la carretera A-312 en la década de los años 


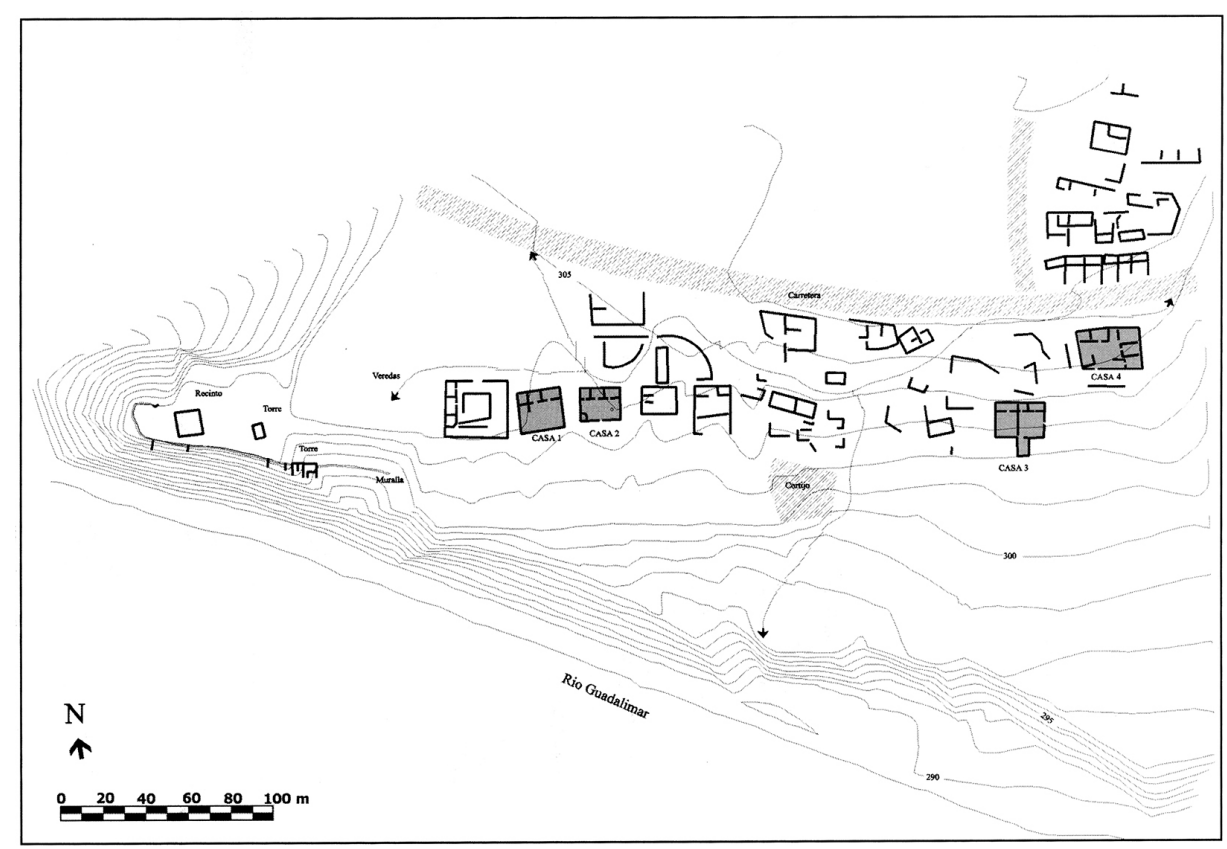

Figura 4. Planta del poblado de La Monaria.

1990 afectó severamente a un área de enterramiento romana que podría atender una cronología amplia desde el Alto Imperio hasta la tardo-antigüedad a juzgar por los restos cerámicos presentes en los olivares cercanos. Manuel de Góngora, sin proporcionar más detalles, propone esta ubicación de Helinga como escenario de una batalla entre Asdrúbal y las tropas romanas, en la vega que el río Guadalén que se abre a los pies mismos del flanco norte de la meseta de Giribaile, controlando una llanura que sería atravesada por el camino de Aníbal, que se consolidaría después como un tramo de la vía Augusta que conectaba con Cástulo.

Esta interpretación está en la base de la reciente propuesta (López y Escobedo, 2015: 89) de identificación de la meseta de Giribaile con el lugar al que Asdrúbal retiró su ejército, ya que había sido utilizado anteriormente como campamento de tropas cartaginesas, situando la población de Baecula en Vilches y el campamento romano de Publio Cornelio Escipión donde actualmente se ubica el poblado de colonización agraria de Guadalén, mediando el escenario de la batalla en la llanura intermedia entre ambos campamentos, púnico y romano (figura 5). Se trata, obviamente, de un planteamiento arriesgado y hasta ahora con falta de un aval científico, que se sustenta en una interpretación sesgada de la documentación disponible que enraíza con una lectura, hoy caduca, de una propuesta arqueológica que se ha visto superada, pero que aún se mantiene viva en la tradición popular y que, por tanto, debe ser investigada convenientemente desde en- 
foques vinculados a la antropología cultural como memoria histórica que ha dejado su huella en las comunidades locales.

\subsection{Los actores y el desarrollo de los acontecimientos}

El mapa de la figura 6 reinterpreta gráficamente la narración de los acontecimientos históricos que Manuel de Góngora lee en el paisaje, tal y como se reproduce en el texto original a pie de página. ${ }^{15}$ En general, no ha resultado un trabajo excesivamente difícil, ya que la mayoría de los topónimos citados se mantienen con igual denominación (ej. el cortijo de la Dehesilla de Rus, la mina de Palazuelos y, por supuesto, los casos de Cástulo y Giribaile) o bajo distintas variantes fáciles de reconocer en la cartografía actual (ej. el barranco de los Ronceles, la loma de los Donceles o la Piedra de Boceles, la Esperilla, Náquer y el Castro de la Magdalena).
La ubicación de los solares de estas antiguas ciudades es el punto de partida para la restitución de una serie de acciones bélicas entre los ejércitos cartaginés y romano en el transcurso de la segunda guerra púnica, incluyendo movimientos de tropas y escenarios de batallas, en cuatro pasos, a saber:

- El desplazamiento de Asdrúbal desde las inmediaciones de Palazuelos, donde había invernado con su ejército, hasta Helinga, y de Escipión el Africano, desde Tarraco hasta Cástulo.

- La marcha del ejército comandado por Asdrúbal desde Helinga hasta Silpia y desde allí a Baecula, llegando anticipadamente a Publio Cornelio Escipión el Africano, que desde Cástulo se dirigió a Baecula.

- Tras la derrota, Asdrúbal huye con el resto de su ejército y sin detenerse en Silpia se asienta en Helinga, donde

15. «Asdrúbal invernaba cerca de las minas de Palazuelos o de Men-Baca, situadas en jurisdicción de la aldea de Carboneros (partido judicial de La Carolina) donde existen, entre otros restos de edificios, tres bóvedas paralelas de extraña construcción y las señales de una explotación inmensa. Estas minas fueron cedidas por el emperador Carlos $\mathrm{V}$ a la ciudad de Baeza, que las utilizó por algún tiempo, conociéndolas hoy el vulgo con el nombre de los pozos de Almivar. Desde allí avanzó el general cartaginés recibidos los socorros que le enviaron los suyos, asentando sus reales en las cercanías de la ciudad de Helinga (Arquillos el viejo), que rodeó con un vallado, colocando sus tropas a la raíz de un altozano (la Dehesilla de Rus o Sierra Morenilla), teniendo a su frente un ancho y dilatado campo a propósito para venir a las manos (los extensos llanos que limitan el Guarrizar, las montańas de Giribaile, Morenilla, la Sierra del Acero, etc., y en donde se levantan los montes de Vilches).

Entre tanto Escipión se encamina desde Tarraco en busca de Asdrúbal, reuniendo sus aliados. Llega a Cástulo; de allí a Baecula (Baeruela, distante dos leguas escasas de Cástulo, cercana a Baeza, que se engrandeció con las ruinas de Baecula). En este medio tiempo los cartagineses desde Helinga habían avanzado, marchando por entre la Piedra de los Donceles, y la Asperilla, a Silpia (ruinas a la orilla derecha del Guadalimar, llamadas hoy los Batanejos), desde donde todavía avanzaron a Baecula.

Vencido Asdrúbal, recorrió los mismos lugares por donde había avanzado sin detenerse en Silpia, punto demasiado cercano a Baecula y poco a propósito por topografía para recoger los restos de un ejército derrotado. Después, un tanto rehechos los penos, se detuvieron o fueron alcanzados en Helinga, y trabada la pelea, Publio Escipión alcanzó una de sus más memorables victorias. Los cartagineses pasaron el Guadalén y huyendo de la estrecha cańada que termina en la Magdalena de Castro, por junto a Naquez, acaso siguiendo las orillas del Guadalimar, intentaron ganar la derecha del Betis. Pero los romanos, encaminándose por la cańada de la Magdalena, les cortaron el paso haciendo en sus enemigos una espantosa carnicería» (Góngora, 1860: 375-376). 


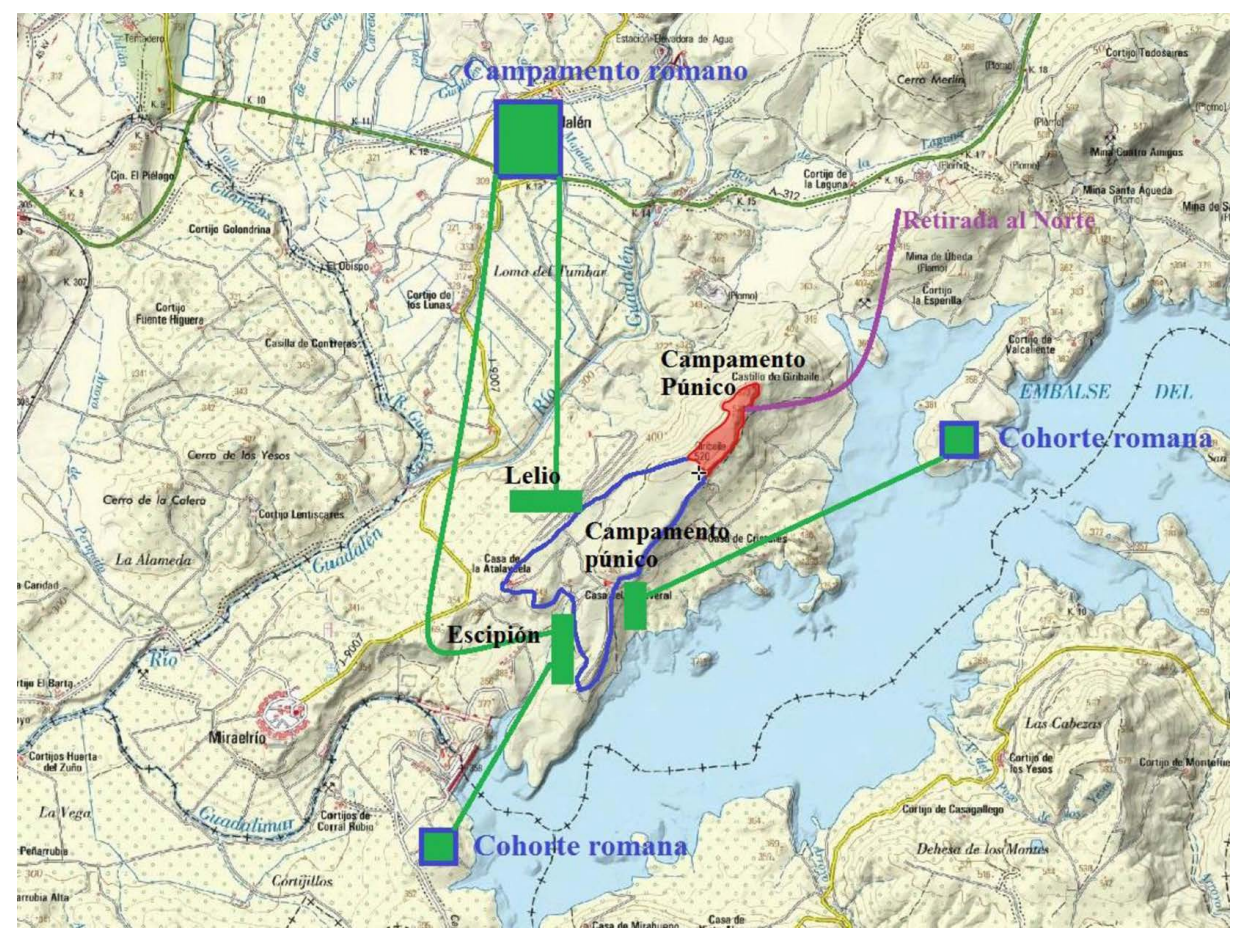

Figura 5. Propuesta de restitución del plano de la batalla de Baecula, según López y Escobedo (2015).

fue alcanzado por Escipión y nuevamente derrotado.

- Segunda huida de Asdrúbal impedida por los romanos a la altura de la cańada de la Magdalena.

Todas estas acciones tendrían lugar en una ventana del territorio que toma como centro geográfico la ubicación de Giribaile. Curiosamente, nada se dice del papel que debió jugar la ciudad en el transcurso de tan importantes acontecimientos. Este silencio resulta significativo cuando se compara la entidad de los restos conservados en Giribaile con relación a las áreas arqueológicas de Arquillos el viejo y La Monaria, la Helinga y la Silpia de Ma- nuel de Góngora, respectivamente. A esto habría que añadir la crítica propia del autor cuando comenta «Quizá se podrá objetar a mis conjeturas anteriores que están muy próximos los lugares de toda esta célebre campaña...» (Góngora, 1860: 376) y la falta de veracidad sobre la identificación de los restos conservados en Baeruela, a la que no vuelve a hacer mención alguna más en el relato de su Viaje Literario.

\section{Lecturas desde una arqueología contextual}

El objetivo de la crítica desde la arqueología científica hacia la arqueología filológi- 


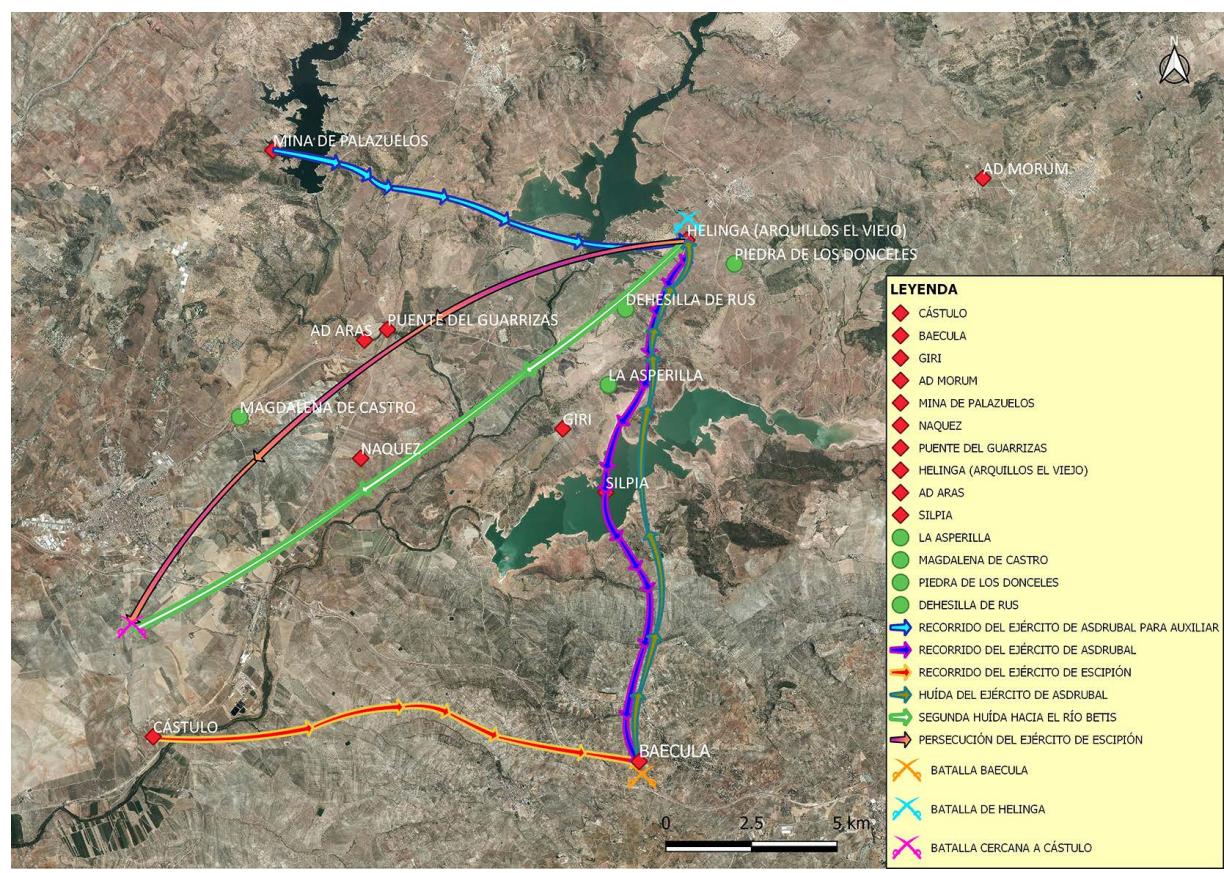

Figura 6. Propuesta de restitución de varias acciones de la segunda guerra púnica, según Manuel de Góngora (1860).

ca no es el de descalificar las propuestas de interpretación pasadas, sino valorar los argumentos planteados a partir de una lectura honesta de las fuentes escritas y de los nuevos datos que proporciona el registro arqueológico. Dentro de este apartado se realiza un estado de la cuestión sobre las aportaciones más recientes que pueden profundizar en el debate sobre la destrucción de Giribaile.

\subsection{Premisas}

Para validar el pasaje que narra la acción de castigo del tribuno Quinto Sertorio en la meseta de Giribaile deberían asumirse dos argumentos básicos: confirmar que la destrucción de la ciudad se produjo a principios del siglo I a. C., y que fue a cau- sa de un ataque y un incendio generalizado. En definitiva, el descubrimiento de Giribaile realizado por Manuel de Góngora en 1860 y su vinculación con Giri es resultado de la búsqueda de una ciudad citada en las fuentes con relación a un pasaje histórico concreto, aunque el supuesto episodio de la destrucción de la ciudad no sería "confirmado» hasta un siglo más tarde con la documentación de un paquete de cenizas en varios de los cortes excavados por Georges Servajean.

Una alternativa más reciente vincula el asedio e incendio de la ciudad al contexto de la segunda guerra púnica, valorando la opción de Orongis (Ruiz et al., 2015; Gutiérrez et al., 2017) y anticipando el trágico final a contextos de finales del siglo III a. C. La identificación de Gi- 
ribaile con la ciudad mencionada por Tito Livio y destruida en el 207 a. C., ha cobrado fuerza en los últimos años con la propuesta de ampliación de la extensión del pago de Cástulo, al objeto de incluir la ciudad de Baecula (Santo Tomé, Jaén), pero obligaría a localizar los campamentos que forman parte de la circunvalatio establecida por Lucio Escipión, hermano de Escipión el Africano.

Ambas interpretaciones comparten la intervención del ejército romano como causa última de la destrucción, asociándola a las guerras de conquista o a las guerras interiores, dos contextos históricos diferentes y separados en el tiempo. Estos hechos, relacionados entre sí, proporcionaban una primera interpretación que debía ser confirmada o revocada por la posterior investigación científica, aunque, como veremos y después de manejar argumentos circulares, esto, por el momento, no resulta fácil. Recientemente, comienza a vislumbrarse un tercer escenario, con un horizonte intermedio entre el final de la segunda guerra púnica y las guerras sertorianas, que por cronología habría que situar hacia la mitad del siglo II a. C., un momento de gran inestabilidad política y social.

\subsection{El proyecto científico}

El inicio de los trabajos de campo en Giribaile tardó algo más de un siglo en llegar, el periodo de tiempo comprendido entre la primera descripción del sitio, debida a Manuel de Góngora en el año 1860, y la realización de varios cortes en la meseta que dirigió el geólogo francés Georges Servajean a partir de 1968. A este periodo de tiempo habría que sumar casi otro medio siglo, con el desarrollo de un programa de excavaciones científicas a partir del año 2014.
Este proceso de investigación científica, limitada y reciente, se completa con una actuación de impacto sobre el paisaje, como fue la construcción de la presa de Giribaile, que está en el origen del desarrollo de sucesivas campańas de prospección. Primero, en los terrenos potencialmente inundables del vaso del embalse, ampliados más tarde al territorio circundante que se relaciona con el hinterland de la antigua ciudad protohistórica y que, actualmente se extiende por la mayor parte de la Comarca de El Condado, realidad administrativa local de organización de esta parte de la provincia de Jaén.

\subsection{Aportaciones desde el territorio}

La primera interpretación histórica de las fases de la secuencia de ocupación de la antigua ciudad de Giribaile proceden de una lectura (indirecta) de los patrones de poblamiento establecidos en el valle a partir del desarrollo de sucesivas campañas de prospección arqueológica desde principios de la década de los años 1990, en un contexto de actuaciones financiadas a bajo coste, previas a la ejecución de las campañas de excavación que han sido propias del proyecto de investigación desde el año 2014.

Como ocurre con otros proyectos con una larga trayectoria de investigación, la interpretación ha ido ofreciendo alternativas diferentes a lo largo de estos ańos, a medida que avanzaba y se construía cada nuevo proceso de trabajo. A veces resulta difícil rastrear a través de las publicaciones los documentos de cultura material que constituyen los fundamentos fijos de la argumentación, de aquellas variables que aportan nuevos factores históricamente significativos acerca del pro- 
ceso abierto de conquista de este territorio ibero a manos de Roma.

A principios de la década de los años 1990 la prospección de los terrenos del vaso del embalse de Giribaile permitió localizar un conjunto numeroso de sitios arqueológicos que, aparentemente, mostraban su dependencia respecto a la ciudad que se ubica en el promontorio cercano y en el que ya se había excavado parte de algunas unidades domésticas a finales de la década de los años 1960. En principio, estos asentamientos debían formar parte de un sistema de ocupación programada de las tierras más fértiles de los valles que circundan Giribaile, concentrándose la mayor parte de estos establecimientos en la vega del valle del Guadalimar, ocupando una franja de río que se ramifica por varios afluentes secundarios y se ensancha en los terrenos más próximos a la meseta (Gutiérrez, 2002).

Recientemente, y aprovechando la retirada de las aguas de áreas de inundación tradicionales de los embalses debido a los largos y cada vez más prolongados periodos de estiaje, ha sido posible revisar algunos de estos sitios arqueológicos y, a la vez, documentar algunos nuevos, en terrenos cada vez más alejados de la ciudad ibérica, localizados al norte, ocupando las riberas que riega el río Guadalén. Hasta el momento no ha sido posible excavar ninguno de estos asentamientos y sólo se cuenta con registros de superficie. La cultura material de estos lugares se corresponde con conjuntos de cerámicas en los que abundan los recipientes de almacenaje, que pertenecen a la secuencia plena y/o tardía de la Cultura Ibérica que se puede reconocer en la meseta de Giribaile, sin poder precisar un periodo de tiempo concreto, aunque podría plantearse un modelo de ocupación estable a partir del asentamien- to de un conjunto numeroso de unidades familiares domésticas (figura 7).

Este horizonte anticipaba la ocupación tardo-republicana del valle que se centralizó en torno al poblado de La Monaria, el cual, desgraciadamente, ha quedado cubierto y perdido definitivamente bajo las aguas del pantano. La propuesta cronológica para este poblamiento de asentamientos asociados al territorio de explotación agrícola organizado desde el oppidum de Giribaile siempre ha tenido en cuenta como fecha límite de amortización la propia de la destrucción de la ciudad, previa, en cualquier caso, a la fundación tardo-republicana de La Monaria, estableciendo, por tanto, una relación de causa-efecto entre ambos acontecimientos.

\subsection{Contextos estratigráficos}

La propuesta cronológica, fundamentada en la estratigrafía horizontal de los registros de colecciones de superficie de los asentamientos establecidos en los valles que rodean Giribaile y asociados a su sistema de explotación económico, además de los resultados de la campaña de microprospección (Gutiérrez, 2010) llevada a cabo en la propia meseta durante los ańos 2004 y 2005, ha podido ser confirmada y precisada, en parte, por los resultados de las dataciones radiocarbónicas de varias muestras procedentes de la apertura de diversas áreas de excavación y por el análisis tipológico-contextual de los conjuntos cerámicos, incluyendo el análisis pormenorizado de algunas piezas diagnósticas.

\subsection{Dataciones absolutas}

A falta de llevar a cabo un estudio estadístico detenido del conjunto de los re- 


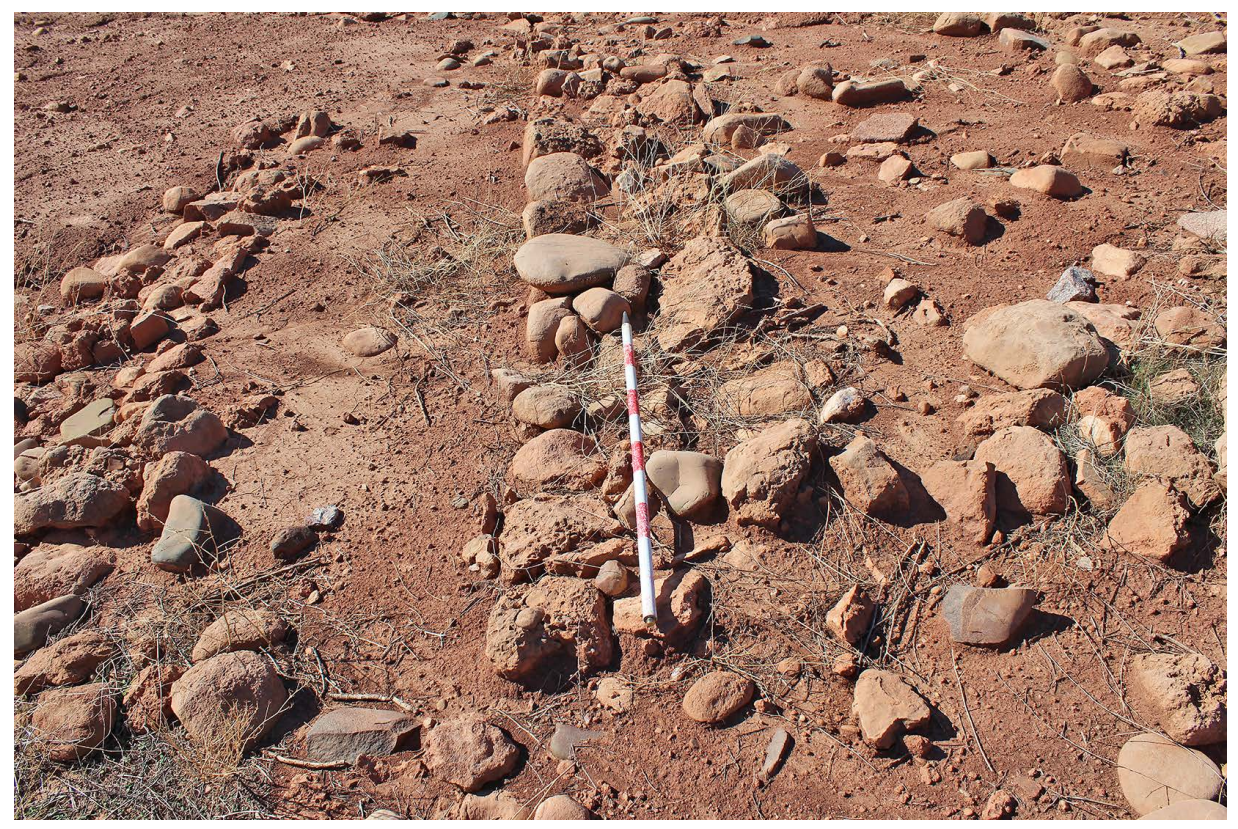

Figura 7. Muros pertenecientes a una unidad de hábitat puesta al descubierto tras la retirada de las aguas del embalse de Giribaile.

sultados de esta clase de análisis específicos realizados en Giribaile, en general, se puede afirmar la presencia de contextos generalizados de excavación pertenecientes a mitad del siglo Iv a. C., que establecerían, posiblemente, el momento de fundación de la ciudad. Aunque no es este el aspecto principal que centra el presente trabajo, es cierto que resulta relevante comprender los orígenes de la ciudad porque contiene algunas de las claves que permitirán analizar, adecuadamente, también su aparentemente trágico final.

Este es un aspecto central del debate actual, porque si bien los paquetes de incendio constatados en algunos de los «pozos de excavación» abiertos a finales de la década de los ańos 1960, han sido confirmados por el proceso de excavación re- ciente en el Área 11 (Ortiz et al., 2019), resulta más discutible su generalización al resto de los cortes abiertos en la meseta. En el caso del Área 3, el ejercicio de la violencia como causa última de destrucción de la ciudad resulta más difícil de establecer a partir de la naturaleza del registro que se genera en el interior de una construcción, la cual se concibe originalmente como un gran espacio abierto de circulación en torno a una estructura circular central, que inicialmente hemos interpretado como un espacio destinado a la estabulación de ganado. Por lo que respecta al Área 2, un corte abierto recientemente que atraviesa de parte a parte uno de los módulos de cajones localizados en el dispositivo de tipo barrera de la muralla, no ha facilitado un registro específico de conflicto asociado a una acción 
de asedio o batalla. En cualquier caso, la línea de investigación prioritaria se muestra continuista con la explicación tradicional, considerando la destrucción violenta de la ciudad como escenario de trabajo preferente.

\subsection{Conjuntos cerámicos}

El conjunto de los materiales cerámicos documentados hasta el momento en Giribaile parece adaptarse bien al horizonte global establecido por las dataciones absolutas que, básicamente, comprende los siglos IV y III a. C. Este marco general, sin embargo, se ve ampliado por los resultados que ofrece la campaña de excavación en el Área 11, ofreciendo un contexto de excavación que debe ser valorado e interpretado convenientemente. De una parte, el almacén de ánforas responde a los esquemas funcionales y compositivos bien conocidos en otros contextos próximos como el Cerro de la Cruz de Almedinilla, de mediados del siglo II a. C., hecho que se vería reafirmado por la presencia de un ejemplar de cuenco que imita la forma Lamb. 27 con cuatro palmetas estampilladas en su fondo interno, en una producción de tipo Kuass (Gutiérrez et al., 2020: 1498).

En todo caso, ninguno de los escenarios contemplados hasta el momento ofrece un horizonte cronológico que se pueda prolongar hasta alcanzar los acontecimientos relacionados con las guerras sertorianas. Este contexto es más propio de los registros que documentamos a principios de la década de los años 1990 en el poblado de La Monaria, al que se asocian algunos fragmentos de imitaciones de cerámicas campanienses en pasta gris y de importaciones de ánforas tardorepublicanas.

\section{Conclusión}

La crítica histórica sobre Giribaile pone sobre la mesa argumentos de naturaleza muy diversa para debatir sobre la importancia de este sitio arqueológico en los principales enfrentamientos bélicos que tuvieron lugar en el territorio de Cástulo entre dos horizontes muy concretos, a saber, la segunda guerra púnica y época sertoriana, asumiendo en ambos casos un final trágico para la ciudad. La entidad del solar de la ciudad en época protohistórica y la monumentalidad de sus defensas destacan como un elemento relevante en la interpretación tradicional y también en los planteamientos actuales, presuponiendo una huella escrita en alguna de las narraciones de estos conflictos.

La primera descripción de Manuel de Góngora en 1860 la relacionó con una ciudad de nombre incierto devastada en una acción de castigo atribuida a Quinto Sertorio. Recientemente, la arqueología científica ha cambiado el escenario hasta retrasarlo al contexto de los acontecimientos que tuvieron lugar durante la segunda guerra púnica en al alto Guadalquivir, llegando a convertirla en la protagonista del episodio de asedio y destrucción de Orongis, acaecido en el 207 a. C. La exégesis filológica de los textos escritos permite determinar los aspectos a favor y en contra de ambas interpretaciones, aunque no la localización precisa de estos lugares en el territorio.

Las aportaciones más recientes de las dataciones radiocarbónicas han abierto un nuevo escenario cronológico intermedio, entre las dos propuestas precedentes, planteando su amortización a mediados del siglo II a. C., a falta de confirmar la destrucción violenta por un ataque romano de toda la ciudad. 
La compensación de este conjunto de datos nos llevaría a decantarnos, en el momento actual de la investigación, por una continuación del periodo de ocupación de Giribaile que sobrepasa los trágicos acontecimientos de la segunda guerra púnica, pero que no alcanza los momen- tos iniciales del siglo i a. C., con lo cual el episodio concreto narrado por Plutarco, con relación a la vida de Sertorio debería buscarse en otra ciudad próxima o bien, con una probabilidad más baja, se vincularía a una ciudad en proceso de decadencia en la meseta de Giribaile.

\section{Referencias bibliográficas}

\section{Fuentes primarias}

Tito Livio. Historia de Roma. La Segunda Guerra Púnica. Tomo II: Libros 26-30. Edición de José Solís y Fernando Gascó (1992). Madrid: Alianza.

Plutarco. Vite parallele. Plutarco: Sertorio-Eumene. Gattinoni. Eumene. Introduzione, traduzione e note di Franca Landucci Gattinoni. Testo greco a fronte. Con un saggio di Philip A. Stadter e contributi di Barbara Scardigli e Mario Manfredini (2004). Milán: Rizzoli.

\section{Fuentes secundarias}

Correa Rodríguez, J. A. (2016). Toponimia antigua de Andalucía. Sevilla: Universidad de Sevilla.

Dolç, M. (1953). Hispania y Marcial. Contribución al conocimiento de la España antigua. Barcelona: Escuela de Filología.

Ernout, A.; Meillet, A. (2001). Dictionnaire étymologique de la langue latine. Histoire des mots. París: Klincksieck.

García Morá, F. (1991). Quinto Sertorio. Roma. Granada: Universidad de Granada.

Góngora, M. (1860). «Viaje literario por las provincias de Granada y Jaén». En: Don Lope de Sosa, crónica mensual de la provincia de Jaén, año 1916 (edición facsímil de 1982). Jaén, 5-8 y 38-39.

Gutiérrez, L.M. (2002). El oppidum de Giribaile. Jaén: Universidad de Jaén.

- (2010). «Microprospección arqueológica en Giribaile (Vilches, Jaén), protocolo de trabajo». Trabajos de Prehistoria, 67 (1), 7-35. <https://doi.org/10.3989/tp.2010.10029>

Gutiérrez, L.M.; López Castro, J.L.; Martínez Hahnmüller, V. (2017). «Giribaile. Una plaza fuerte cartaginesa en el contexto de la ocupación bárquida del Alto Guadalquivir». En: Prados, F.: Sala, F. (eds.). El oriente de occidente. Fenicios y púnicos en el área ibérica. Alicante: Universitat d'Alacant, 385-401.

Gutiérrez, L.M.; Ortiz, A.J.; Alejo, M. (2020). «Reflexiones desde el proyecto Giribaile sobre la presencia púnica y cartaginesa en el alto Guadalquivir». Mytra, 5, 1495-1504.

Gutiérrez, L.M.; Royo, M.A.; Bellón, J.P.; Barba, V. (1999). «La Monaria, análisis de un poblado del siglo i a.n.e. en el Guadalimar (Vilches, Jaén)». XXIV Congreso Nacional de Arqueología 4. Murcia: Gobierno de la Región de Murcia e Instituto Histórico Español, 753758. 
Konrad, C.F. (1994). Plutarch's Sertorius: a historical commentary. Chapel Hill: University of North Carolina Press.

López, J.A.; Escobedo, E. (2015). «Los caminos ibéricos y la batalla de Baécula». En: EscobeDo, E.; López, J.A.; Cabrera, M. (coords.). III Congreso Virtual sobre Historia de las Vías de Comunicación. Jaén, 73-92.

Ortiz, A.J.; Gutiérrez, L.M.; Alejo, M. (2019). «Más que adobes. La construcción con tierra durante los siglos IV-III a. C. en el Área 11 de Giribaile (Vilches, Jaén)». Lucentum, 38, 171 187.

<https://doi.org/10.14198/LVCENTVM2019.38.08>

Pérez Vilatela, L. (1994). «Los gurisinos». El miliario extravagante, 48, $2-4$.

Ruiz, A.; Bellón, J.P.; Molinos, M.; Rueda, C.; Gómez, F. (2015). «La visibilidad arqueológica de un acontecimiento: las contradicciones de la arqueología histórica». En: BELlón, J.P.; Ruiz, A.; Molinos, M.; Rueda, C.; Gómez, F. (eds.). La segunda guerra púnica en la peninsula ibérica. Baecula, arqueología de una batalla. Jaén: Universidad de Jaén, 621-636.

Schulten, A. (2013). Sertorio. Traducción de M. Carreras. Sevilla: Renacimiento (reimp. de la traducción española de 1949 de la $1^{\text {a }}$ ed. en alemán 1926).

Serrano, J. L. (2004). «Las fortificaciones de Orongis/Aurgi». Arqueología y Territorio Medieval, II.2, 11-22. <https://doi.org/10.17561/aytm.v11i2.1690>

Servajean, F.; Servajean, G.; Castillejo, A. (1986). «De Giri a Guiribaile: análisis de una posible correspondencia entre Giri y Guiribaile». Boletín de la Asociación Española de Amigos de la Arqueología, 22, 37-46.

VIllar, F. (2014). Indoeuropeos, iberos, vascos y sus parientes. Estratigrafía y cronología de las poblaciones prehistóricas. Salamanca: Universidad de Salamanca.

Yelo, A. (1991-1992). «Orongi». Anales de Prehistoria y Arqueología, 7-8, 173-176.

Ziegler, K. (1934) «Plutarchstudien». Rheinisches Museum für Philologie, 83, 1-20. 